University of Montana

ScholarWorks at University of Montana

Graduate Student Theses, Dissertations, \&

Professional Papers

1979

\title{
Effects of type of information and method of dissemination on the reporting of a shoplifter
}

Bonnel A. Klentz

The University of Montana

Follow this and additional works at: https://scholarworks.umt.edu/etd

Let us know how access to this document benefits you.

\section{Recommended Citation}

Klentz, Bonnel A., "Effects of type of information and method of dissemination on the reporting of a shoplifter" (1979). Graduate Student Theses, Dissertations, \& Professional Papers. 5614.

https://scholarworks.umt.edu/etd/5614

This Thesis is brought to you for free and open access by the Graduate School at ScholarWorks at University of Montana. It has been accepted for inclusion in Graduate Student Theses, Dissertations, \& Professional Papers by an authorized administrator of ScholarWorks at University of Montana. For more information, please contact

scholarworks@mso.umt.edu. 


\section{THE EFFECTS OF TYPE OF INFORMATION \\ AND METHOD OF DISSEMINATION ON THE \\ REPORTING OF A SHOPLIFTER}

By

Bonnel A. Klentz

B.A., University of Kansas, 1976

\section{Presented in partial fulfillment of the requirements for the degree of

1979

Approved by:
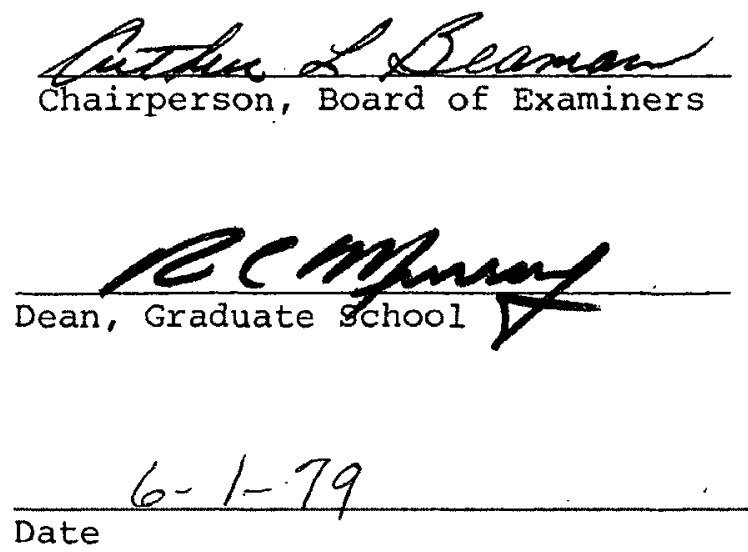
UMI Number: EP41078

All rights reserved

INFORMATION TO ALL USERS

The quality of this reproduction is dependent upon the quality of the copy submitted.

In the unlikely event that the author did not send a complete manuscript and there are missing pages, these will be noted. Also, if material had to be removed, a note will indicate the deletion.

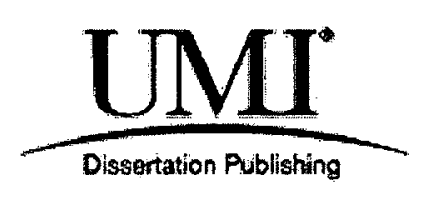

UMI EP41078

Published by ProQuest LLC (2014). Copyright in the Dissertation held by the Author.

Microform Edition (C) ProQuest LLC.

All rights reserved. This work is protected against unauthorized copying under Title 17, United States Code

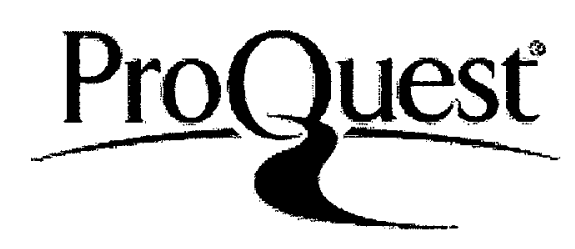

ProQuest LLC.

789 East Eisenhower Parkway

P.O. Box 1346

Ann Arbor, Ml 48106 - 1346 
The Effects of Type of Information and Method of Dissemination on the Reporting of a shoplifter

\section{Director: Arthur L. Beaman $\mathbb{Q} / \mathcal{B}$}

The present study demonstrated increased reporting rates of a staged shoplifting in a university bookstore. Two methods of information presentation (lecture format, mass-media campaign) succeeded in producing these effects. The type of information given to 72 male and 99 female students was also varied and included: 1) how and why to report shoplifting, 2) the socialpsychological factors which inhibit shoplifting, and 3) a combination of these. All types of information increased the reporting rates compared to the control groups. The lecture format increased reporting rates above that of the mass-media groups. No sex differences were found. The findings have implications for the way factual knowledge and attitudes interact in influencing behavior. 
TABLE OF CONTENTS

Page

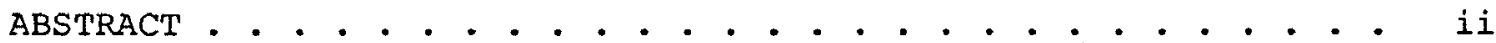
LIST OF TABLES . . . . . . . . . . . . . . . . . . . . . . . . v

Chapter

1. LITERATURE REVIEW . . . . . . . . . . . . . . . . . . 1

Emergency Helping Research . . . . . . . . . . I

Characteristics of Bystander . . . . . . . . 9

Characteristics of Subjects . . . . . . . . 14

Characteristics of Victim . . . . . . . . 19

Characteristics of Emergency . . . . . . . . 22

Increases in Helping Behavior . . . . . . . . 23

Shoplifting Research . . . . . . . . . . . 26

2. PROPOSED RESEARCH . . . . . . . . . . . . . 32

3. METHOD . . . . . . . . . . . . . . 34

Subjects and Brief Overview . . . . . . . . 34

General procedure ............... 34

Check on the Manipulation ........... 36

Second Session and Dependent Variables . . . . . . 36

Attitude Questionnaire . . . . . . . . . . 38

4. RESULTS . . . . . . . . . . . . . . 39

Check on the Manipulations . . . . . . . . . 39

Major Dependent Variables . . . . . . . . . 40 
Attitude Questionnaire . . . . . . . . . . 42 42

5. DISCUSSION . . . . . . . . . . . . 45

Speed of Response :. . . . . . . . . . . . . 49

Method of Reporting . . . . . . . . . . . . . 49

Suspicious Subjects . . . . . . . . . . 50

Sex Differences ............. . . 51

Possible Confounding Variables . . . . . . . . 51

Attitude toward shoplifting . . . . . . . . 52

REFERENCE NOTES . . . . . . . . . . . . . . . . . . 55

REFERENCES . . . . . . . . . . . . . . . . . . . . . . 56 


\section{LIST OF TABLES}

Table

Page

1. Predicted Responses of Observer ............ 61

2. Percentage of People Reporting as a Function of Type of Information and Method of Dissemination . . . . . 62

3. Percentage of Nonsuspicious Subjects Reporting as a Function of Type of Information and Method of Dissemination ............... 63 


\section{Chapter 1}

\section{LITERATURE REVIEW}

\section{EMERGENCY HELPING RESEARCH}

The study of emergency helping behavior began as a function of Kitty Genovese's murder in 1964. It is well known that Ms Genovese was murdered while thirty-eight neighbors witnessed the crime. Although the murder took over thirty minutes, during that time not one witness called the police or offered direct assistance. Sociologists and psychiatrists were asked to explain this behavior (Rosenthal, 1964). Among the many explanations offered, it was suggested the murder vicariously gratified sadistic impulses, it was a function of TV violence, or it resulted from depersonalization. However, the most widely postulated reason for the nonintervention was apathy.

John Darley and Bibb Latané were the first two researchers who experimentally studied emergency helping behavior. In 1968 with the publishing of the first study in this area numerous individuals began to investigate aspects of the emergency situation to determine why individuals do or do not help.

Darley and Latané began their research on emergency helping behavior by considering how an emergency situation differs from nonemergency situations. The most distinctive characteristic of an emergency is that it involves threat or harm not only to those initially 
involved but also to anyone who, intervenes (Latané \& Darley, 1969). Therefore, the possible harmful consequences of intervention may inhibit helping.

A second characteristic of an emergency is that it is an unusual and rare event. Consequently, very few people will actually encounter an emergency. Unfortunately, if one is encountered an individual most likely will have had no direct experience in how to handle it. Emergencies also are very different from one another and each must be responded to uniquely. Actions initiated in response to a fire would be inappropriate in the case of a drowning. Two final characteristics of emergencies are that they will develop suddenly without warning and instant action is required. This means a person must act without forethought and there is little time for considerations of possible alternatives. Therefore, an individual confronted with a rare event without warning, and having no personal experience in responding to the event may ignore it or distort their perceptions of it rather than face possible harm (Latané \& Darley, 1969).

Two models have been proposed to explain an individual's behavior specifically in an emergency situation. These are the decision model proposed by Latané, and Darley (1969) and the cost-reward model proposed by Piliavin and Piliavin (1969).

Latané and Darley's decision model simply states that before an individual will help (or not help) in an emergency situation he/she goes through a series of decisions (Latané \& Darley, 1969). First, the emergency must be noticed. Only if it is seen can there be any hope of intervention. Once the person is aware of the event it must be interpreted as actually being an emergency. (Is the man on the 
sidewalk drunk or has he just had a heart attack?) The next decision concerns who is responsible to act. (Perhaps someone else is more qualified.) Finally if the person notices an event, interprets it as an emergency and feels responsible to act the person must decide what form of assistance should be given and how to implement this choice. (Should the police be called? Where's the nearest phone? Is there a hospital nearby?) According to this model of helping, failure to intervene may be a function of not noticing the event, failing to interpret it as an emergency, not feeling responsible to act or not being competent or qualified to intervene.

Darley and Latané (1970) further propose that this decision process is affected by the presence of other people. If all the other witnesses to an emergency do not respond and seem to regard the event as nonserious, this "consensus" has a strong effect on the response of any one individual (later termed social comparison). Also, bystanders are concerned about others' expectations and evaluations of their behavior. An individual doesn't want to appear foolish by reacting to a nonemergency (audience inhibition, later termed evaluation apprehension). A final factor is diffusion of responsibility. When more than one observer is present the pressure to intervene does not focus on any one observer, but is shared by all. As a result, each is less likely to help.

Piliavin and Piliavin's model of helping is a more complicated model to explain emergency helping behavior and is based upon equity theory (Walster \& Piliavin, 1972). The major propositions of the model are: 
1. Observation of an emergency causes arousal in the individual. This arousal consists of cognitive components (empathy, disgust, curiosity) and physiological components (rapid heart beat, shortness of breath, "butterfies in the stomach").

2. The more arousal the more likely the individual is motivated to reduce it.

3. (a) Three aspects of the emergency situation determine the degree of arousal: severity of the emergency, physical distance to emergency, and perceived similarity or emotional attachment to victim.

(b) Three personality factors should have a strong impact upon an individual's arousal: self-esteem, denial repression vs. sensitization, and sensitivity and responsivity to needs of others.

4. An individual's response to an emergency will be one which most rapidly and completely reduces arousal, and one which incurrs as few net costs (costs minus rewards) as possible.

There are two types of costs which may be incurred. These are: costs to the bystander for helping (loss of time, danger, exposure to disgusting experience) and costs for not helping (self-blame, public censure and loss of rewards). Table 1 presents Piliavin and Piliavin's predictions of the most likely response of a moderately aroused bystander as a function of costs of direct help and the costs for not helping the victim (Walster \& Piliavin, 1972).

Insert Table 1 about here

Direct comparison of these two models is not possible since no study has conclusively demonstrated one model to be superior or has 
accounted for all the data. Also several of the assumptions contained in Piliavin and Piliavin's model have yet to be experimentally tested. These include personality factors and determinants of arousal. However, judging the heuristic value of both models, it appears Darley and Latané's model is more widely researched and accepted. This may be partially due to the relative simplicity of their model. The first emergency helping studies (Darley \& Latané, 1968; Latané \& Darley, 1968) tried to duplicate in the laboratory what actually occurred the night of Kitty Genovese's murder. That night thirty-eight people watched as Kitty Genovese was murdered each from their own home or apartment. Darley and Latané (1968) proposed that since the behavior of each bystander could not be observed it was assumed that "somebody must be doing something". To test this in the laboratory, subjects were ushered into individual booths and heard another "subject" undergoing a severe epileptic-like fit. The major independent variable was the number of other people the real subject believed also heard the fit. The subject believed either she alone heard the emergency, she and one other "subject".heard the emergency, or she and four other "subjects" heard the emergency. It was found the group size had a significant effect on the subject's behavior. When alone 858 reported the seizure, with one other bystander $62 \%$ reported it and with four other bystanders 318 reported the emergency. It was concluded that as the number of bystanders increase, responsibility is diffused and it is assumed by the individual when the other witnesses behavior can't be seen that "someone else must be doing something".

Variations upon the three person group (subject, victim and 
bystander) were also run in this study. The "perceived bystander" was varied to be a male, female or a premedical student who worked in an emergency ward at Bellevue Hospital. These variations had no effect upon the subjects' (females) frequency or speed of response. Darley and Latané (1968) explained this by differentiating between direct and reportorial intervention. Direct intervention breaking up a fight) often requires physical power, or a specific skill, while reportorial intervention is simply reporting an emergency to someone qualified to handle it. Since subjects in this study reported the emergency rather than taking direct action no special qualifications were required. Therefore responsibility was not diffused to males or a more medically competent person. Only when the number of bystanders increased was there a significant decrease in helping.

The second study by Latane and Darley (1968) looked at the social influence process that occurs during the interpretation of an event. They hypothesized that an individual who'views the passive reactions of others is less likely to respond than when witnessing the event alone. While filling out a questionnaire subjects were exposed to a possible emergency (smoke coming into the room). The subjects were either alone, with two bystander who were also subjects, or with two nonreactive confederates. Latané and Darley's hypothesis was confirmed. The emergency was reported $75 \%$ of the time when subjects were alone, $38 \%$ of the time with three actual subjects and $10 \%$ of the time when one subject was paired with two nonreactive bystanders. It was concluded this effect is due primarily to social influence processes since diffusion of responsibility should not occur in a situation where the subject also is in possible danger. It is of interest to 
note that two conditions in this study contained groups of three subjects. One condition contained three "naive" subjects and the other one subject and two nonreactive confederates (trained to respond with "I don't know" if asked anything about the smoke). Yet the' former condition produced a $38 \%$ helping rate and the latter $10 \%$. Apparently something other than diffusion of responsibility was occurring since the number of persons present to diffuse responsibility to was the same in both conditions yet the results differed. It probably can be explained by the fact that nonreactive confederates led the subjects to believe the situation was not as serious as in the other condition when "naive". subjects may have given startle reactions that led subjects to consider the situation more serious.

On the basis of these studies Darley and Latane concluded the witnesses of Kitty Genovese's murder were not apathetic. Instead each individual diffused responsibility to the others and assumed someone must be doing something.

It should be noted that Darley and Latané talk about the social influence process in their 1968 studies yet do not differentiate between social comparison and evaluation apprehension. The first study to investigate these two processes separately was Beaman, Fraser, Diener, Kelem and Westford (Note 1 ). Subjects were run in four conditions; alone, an evaluation apprehension condition (confederate could see subject), a social comparison condition (subject could see confederate), and a combined evaluation apprehension and social comparison condition (both subject and confederate could see éach other). Helping rates for these groups were $80 \%, 75 \%, 55 \%$, and $25 \%$, 
respectively. The data show that evaluation apprehension by itself did not significantly decrease helping behavior. However, the social comparison subjects did show a significant decrease in helping. The group with the combination of evaluation apprehension and social comparison, which in all othex research had been considered just the social influence process, showed the largest decrease in helping responses. Although evaluation apprehension by itself had no effect, when paired with social comparison a helping rate significantly lower than the social comparison variable by itself resulted.

This differentiation was again made by Schwartz and Gottlieb (1976). They criticize Beaman et al. (Note 1) for not including a condition in which the subject neither observed nor was observed by the confederate (diffusion of responsibility). However, Beaman et al. controlled for diffusion of responsibility by leading subjects to believe that the confederate's room had a broken door latch and could not be opened from the inside.

Schwartz and Gottlieb's subjects were run in individual booths connected by microphones; no visual contact was made. Subjects were run in five conditions; alone, diffusion of responsibility (no microphone on), social comparison (only confederate's microphone on), evaluation apprehension (only subject's microphone on), and both social comparison and evaluation apprehension (both confederate's and subject's microphone on). When alone, subjects helped 928 of the time. There was a significant decrease in helping in the diffusion of responsibility condition (helping rate 45\%). Evaluation apprehension and social influence were not found to interact in their effect on helping and so they were treated independently. Evaluation 
apprehension significantly increased helping responses. Seventy-four percent helped when others were aware of their reaction, whereas $39 \%$ helped when others were not aware of their reactions. However, social comparison had no significant effect on helping. These data do not conform to earlier established findings.

This study by Schwartz and Gottlieb has a number of problems which make the results questionable. For example, subjects were aware of the bystander, and vice versus, only through their microphone connection; no visual contact was established. Further research appears necessary before the exact impact of evaluation apprehension and social comparison processes on helping responses can be determined.

Soon after the initial studies by. Latané and Darley, studies followed which investigated all aspects of the emergency situation. Consequently, the review of these articles will be divided into four areas. These are: characteristics of the bystanders, characteristics of the subjects, characteristics of the victim and characteristics of the emergencies themselves.

\section{Characteristics of Bystander}

Bystanders in emergency helping literature have been investigated a number of ways. These include manipulating the bystander's relationship to subject, manipulating the ability of the bystander to help, manipulating the interpretation of the event by the bystander and manipulating the sexual composition of the bystander group.

There are too few studies which investigate the effects of a bystander who is a friend of the subject to draw any firm conclusions. It is assumed friends are less likely to misinterpret each others initial reaction and less likely to fear possible embarrassment. 
Therefore, groups of friends should help a person in need more than groups composed of strangers.

Latane and Rodin (1969) tested this-by comparing the helping rate of alone subjects to the helping rate of two subjects who were strangers and finally with two subjects who were friends. When alone, subjects responded to a lady in distress 708 of the time. When two strangers were paired, helping occurred in only $40 \%$ of the dyads, which is significantly less than the 708 that helped when two friends were paired. Although it appears that friends were just as likely to intervene as someone who was alone, such is not the case. There are twice as many people available to help when groups of two are run, thus one would expect an increase in the helping rate just by chance. Therefore, based on the helping rate of subjects that were alone, friends were less likely to help $(p<.10)$. They also reponded significantly slower.

The only other study to look at the effects of friends versus strangers was Clark and word (1972). However, instead of running two naive subjects who were friends they asked the confederates of the study to bring in their friends to be run as subjects. In this study the confederate either reacted or didn't react to a man in distress while with a stranger or with their friend. Across all situations they found a $100 \%$ helping rate. Clark and Word explained the difference of these results with the results found by Latané and Rodin (1969) by compairing the ambiguity of the two emergency situations. Clark and Word's emergency was not at all ambiguous and quite serious, while Latané and Rodin's emergency was taped and injury to the victim appeared minimal. 
Related to friendship of the bystander and subject is their perceived similarity. This relationship occurs because it has been found that people tend to like others who are similar to themselves, particularily if the basis for similarily is attitudes. Smith, Smythe and Lien (1972) and Smith, Vanderbilt and Callen (1973) manipulated the similaxity of a confederate to the subjects. ${ }^{\text {This }}$ was done by having the subject complete an attitude questionnaire. A similar "subject" was manufactured by generating responses on the confederate's questionnaire that were similar to the real subject's. The subject then was able to look at the confederate's questionnaire and see the similarities in attitudes. It was found that if a perceived similar subject (confederate) does not react to an emergency, the real subject is less likely to help than if a perceived dissimlar subject does not react (5\% vs. $35 \%$ helping rates, respectively). In the second study, (Smith et al., 1973) a dissimilar and similar confederate either reacted to an emergency in an alarmed or in an unconcerned manner. It was fouund that the reaction of the confederate had a stronger effect on subject's behavior than did similarity. Subjects helped significantly more in the alarmed condition with no differences found for perceived similarity. One might conclude that if the situation is ambiguous and an individual has no cues as to the interpretation of the event, the individual will then look to those most similar to him/herself to determine the most appropriate response.

The results of Smith et al. (1973) have also been found in a number of other emergency helping studies (Korte, 1971; Bickman, 1972; Darley, Teger \& Lewis, 1973; Staub, 1974). Korte (1971), Bickman (1972), and Staub (1974) had bystanders verbalize their de- 
finition of the situation. It was consistently found that when the bystander defined the situation as an emergency there was a significant increase in helping over no definition and a significant decrease in helping if the situation was defined as a nonemergency. Darley et al. (1973) simply had two naive subjects either face each other or sit back to back. When facing each other the startle reactions to the emergency were clearly visible and the helping rate reached $80 \%$ as compared to a $20 \%$ helping rate when the subjects were not facing each other.

These studies clearly show a social influence effect on helping behavior supporting Darley and Latané's model (1970) of helping. Further support for their model was found by Bickman (1971, 1972). By manipulating the ability of the bystander to help (not able, able) it was found when the bystander was not able to help (was in a seperate building) the subject didn't diffuse responsibility but helped almost as often as when alone; $75 \%$ vs 808 , respectively. When the bystander was able to help (in the same building) subjects helped significantly less; $40 \%$ and diffused responsibility.

Perhaps another definition for bystander inability to help is that used by Ross $(1971,1973)$. With the use of two children (1971) and a blind person (1973), Ross attempted to focus responsibility upon the subjects. Not only should these bystanders increase responsibility but they should also fail to serve as cue sources in the social comparison process. However, it was found the child's nonreactive cues were important in interpreting an emergency (1971). Two emergencies were utilized; smoke coming into the room and a workman in distress. In spite of the type of emergency there was the 
greatest amount of helping when the subject was alone (100\%) and least amount when the subject was paired with two adult nonreactive bystanders $(16 \%)$. When two nonreactive children were present $50 \%$ of the subjects helped showing an intermediate amount of helping. These results were partially replicated when a blind nonreactive bystander was introduced (Ross, 1973). The difference was an increase over the alone condition during the smoke emergency. Since the blind person was unable to see the smoke pouring into the room it is unlikely the subject would use the blind nonreactive bystander as a cue source. These studies show that given an ambiguous event even the social cues of dependent others may be used in interpreting emergencies.

Conceivably, the opposite of a dependent other is the effect of a competent bystander on the diffusion of responsibility. In emergency helping studies a competent bystander has become synonymous with a medical intern. This bystander variable has been investigated in a number of studies (Darley \& Latané, 1968; Schwartz \& Claussen, 1970; Piliavin \& Piliavin, 1972; Piliavin, Piliavin \& Rodin, 1975). As was mentioned earlier Darley and Latané found no diffusion of responsibility when a competent other was introduced. Schwartz and Claussen (1970) using the same paradigm as Darley and Latané did find a diffusion of responsibility effect for female subjects. However, Schwartz and Claussen used a much stronger competence manipulation by elaborating on duties performed in the emergency room: "Holding down some drunk, or a screaming kid, while the doctor puts 20 stitches in their head. . ." (p. 308). 
Both Piliavin and Piliavin (1972) and Piliavin, Piliavin and Rodin, (1975) while looking at the effect of a competent other were primarily concerned with characteristics of the victim and their effect on helping. All significant effects found in these studies were due to these victim characteristics, although the presence of an intern produced marginally significant lower helping rates $(p<.08)$.

The last bystander variable to be manipulated was the sexual composition of the bystander group (Ruch, Newton \& Kough, Note 2). This was varied (same or mixed sex, two person groups) to determine the effect on helping behavior. The results of the study show a woman fainting received less help from mixed sex groups than a group consisting of two males or two females. In the mixed sex groups, 608 of the males and 508 of the females helped, whereas in same sex groups, $90 \%$ of the females helped and $80 \%$ of the males helped. However, no tests of significance were computed and same sex groups: data are based on percent of groups that intervened, whereas mixed sex groups' percentages are based on individual data. More research should be done before the effect of sexual composition of the bystander group can be determined.

As has been shown, bystander variables are extremely important in Daxley and Latané's model of helping. These variables effect the interpretation of the situation, the focusing of responsibility, and ultimately the intervention in an emergency situation. Characteristics of the Subjects

Characteristics of the subject which have been investigated are: demographic variables, dispositional variables and age. A number of demographic variables have been studied to determine 
their effect upon helping behavior. The only one that has shown a correlation with helping, is the size of the community in which the subject grew up $(x=-.26$, Darley \& Latané, 1968). Recently, just the opposite was found to be true (Weiner, 1976). Varying community size from 10,000 and below (rural), 325,000 (Honolulu, this study took place in Hawaii), and 500,000 and above (mainland urban) it was found rural raised individuals helped significantly less overall than either urban group. Weiner, also varied sensory overload (high and low) of the subjects while the emergency occurred. The high-overload condition attempted to simulate the noise and distractions of a large urban community by having the subject watch slides and listen to a tape recording while answering questions on a complex answer sheet. In this condition no differences in helping rates were found for any of the rural or urban groups; helping rates were low for all groups. However, in the low-overload condition (more of a leisurely atmosphere, first watching slides, then listening to a tape, finally answering questions on a simple answer sheet) the two urban groups helped significantly more than the rural groups although there was no difference in task performance. Perhaps, the people from large communities have adapted to overload in their environments. Therefore, a small amount of overload would not interfere with the processing of other stimuli such as cries for help. Whereas, people from rural communities not used to an excess of environmental stimuli perhaps tune out everything but the task at hand.

Personality variables have been no more effective than demographic variables in predicting helping behavior in an emergency situation. Numerous variables such as social responsibility, need 
for approval, machiavelianism, and responsibility denial have been ineffective in predicting helping behavior (Darley \& Latané, 1970; Schwartz \& David, 1976). However, Wilson (1976) has looked at esteemoriented persons vs. safety-oriented persons and has found a significant difference in subsequent helping behavior. Safety-oriented individuals are characterized as being highly anxious, passive, dependent and having strong feelings of personal incompetence. Esteemoriented individuals are 'characterized as assertive, achievementoriented, and have strong feelings of personal adequacy. Three groups of subjects (safety-oriented, a middle group, and esteemoriented) were run alone and with two passive bystanders. It was found esteem-oriented individuals helped significantly more than either the middle group or the safety-oriented individuals. This was true in both the alone (968 vs $65 \%$ and $55 \%$, respectively) and passive bystander conditions ( $71 \%$ vs $23 \%$ and $17 \%$, respectively). It seems people with strong feelings of personal adequacy are more likely to initiate action inspite of social influences. However, further testing of this personality variable should be completed to determine the consistency of this finding.

Very similar to personality variables is religiosity. Intuitively, it seems very religious individuals would help more than would nonreligious individuals. This has not been supported, however (Darley \& Batson, 1973; Annis, 1976). On the basis of the Good Samaritan Parable, Darley and Batson investigated the effects of religiosity and hurry on helping. Theology students were asked to give a short talk on either the Good Samaritan Parable or job opportunities for theologians. Subjects were then sent to another building 
either in a hurry, on time, or in no hurry. Enroute to the other building, subjects encountered the emergency; a man slumped in a doorway. The only significant effect found in this study was for the hurry variable. Subjects in a hurry helped $10 \%$ of the time, when they were on time they helped $45 \%$ of the time and when they were in no hurry, $63 \%$ helped. Thinking religious thoughts had no effect on helping.

However, Greenwald (1975) reanalysed Darley and Batson's data using a Bayesian approach. This reanalysis showed that an alternative hypothesis (reading the parable increased the odds of helping by more than 50\%) was favored over their no significance conclusion. Greenwald concludes that given Darley and Batson's data reanalysed, further research in necessary.

Darley and Batson's conclusions were supported by Annis. (1976). No significant correlation with helping was found for 3 areas of religious behavior:

1. degree of commitment to traditional beliefs

2. location of religious value in the individual's heirarchy of values

3. church attendance and prayer frequency. Based on the data presently available, religiosity and religious behaviors appear to be no better predictors of helping than do demographic or personality variables.

Staub (1970a, 1970b, 1971a, 1971b) carried out a series of studies looking at the emergency helping behavior of children. Staub (1970a) found that for lst graders focusing responsibility upon the child increased helping behavior. However, this effect was not found 
for kindergarten aged children. Staub's next study (1970b) in this series looked at changes in helping behavior when alone or with a peer as a function of age. Subjects included kindergarten children through 6 th grade. When in pairs children helped significantly more than when alone: just the opposite of what has been repeatedly found for adults. This reversal might be due to a reduction of fear or stress, produced by the emergency, when in the presence of another child (Staub, 1970b). A curvilinear relationship between age and helping was found. Kindergarten and 6 th graders were equally low in responding to a child in distress whether alone or in pairs. Perhaps kindergarten age children have not internalized the norms appropriate for the situation and thus do not help. This low frequency of helping for sixth graders may be caused by fear of disapproval by the experimenter for initiating action (Staub, 1970b).

To determine if this was actually the case, Staub (1971b) manipulated permission or prohibition to enter the room in which the emergency occurred. For seventh graders there was a significant increase in helping behavior when permission was granted to enter the adjoining room as compared to no information and when entering the room was prohibited. For adult females it was found, permission to enter the adjoining room where the emergency occurred and no information about entering the room had the same significant effect in increasing helping behavior when compared to individuals prohibited from entering the adjoining room. Staub-(1971b) explains these differences between adults and children in the no information groups two ways. First, inappropriate behavior for seventh graders (going into a strange room) may not seem inappropriate for adults. Second, the 
ability to determine when certain behaviors supercede situationally more appropriate behaviors, increases with age.

Staub's series of studies have shown that children's helping behavior is not the same as that of adults. The social influence process is not always inhibiting for children and no information concerning the appropriate behavior in a situation is the same as prohibition. It remains to be seen how other adult inhibitors of helping behavior affect children's helping.

Characteristics of the Victim

Investigating the effects of characteristics of the victim on helping behavior applies primarily to Piliavin and Piliavin's model of helping. Victim variations (blood-no blood, drunk-ill) affect the costs for helping and the costs for not helping, therefore predictions as to individuals' helping responses can be made on the basis of Piliavin and Piliavin's cost matrix (Table 1). The types of victim variations investigated by the piliavins and their associates include whether the victim is drunk or ill, black or white (Piliavin, Rodin \& Piliavin, 1969), presence or absence of blood (Piliavin, \& Piliavin, 1972) and the presence of absence of a "port wine stain" birthmark on the victim's face (Piliavin, Piliavin \& Rodin, 1975). Those victim variations which increase the cost to the bystander for helping (drunk, presence of blood or birthmark) should produce a decrease in helping and this has been found consistently.

The method employed to investigate these variables by the Piliavins and their colleagues consists of a team of four people boarding a subway. Soon after the subway car begins to move the 
victim falls to the floor of the train. Observers measure response time and the number of people helping in each situation. Using this method, several assumptions proposed in Piliavin and Piliavin's model are difficult to measure. These include personality characteristics and the measurement of arousal.

Gaertner and Dovidio (1977) have measured physidlogical arousal through heart rate and conclude their findings support the Piliavin's model of helping. It was found the greater the increase in heart rate, the more quickly subjects intervened in an emergency situation. In a second experiment by Gaertner and Dovidio (1977) it was found if this physiological arousal caused by the emergency could be attributed to a pill, helping was slower.

The main thrust of Gaertnex and Dovidio's study lopked at the effect of helping as a function of race of the victim. They found when no bystanders were present, white subjects didn't discriminate against blacks; blacks were just as likely to receive help as whites. However, in the presence of other bystanders whites were more likely to diffuse responsibility with a black victim thus decreasing helping behavior and heart rate.

Piliavin, Rodin and Piliavin (1969) also investigated the effect of race of a drunk or ill victim and found some tendency for same-race helping to occur more frequently. This tendency increases when the victim is drunk as compared to when he is ill.

Sex might also be an important variable in determining whether help will be given. The sex of a physical assault victim has been studied by Borofsky, Stollack and Messe (1971) and Shotland and Straw (1976). Borofsky et al. staged a physical assault in which they varied 
the sex of both the assaulter and victim; male assaulter, female victim; male assaulter, male victim; female assaulter, female victim; female assaulter, male victim. It was hypothesized males would help more than females and males would intervene most often when a female was the victim particularly when being assaulted by a male. Subjects were part of a six person group which included the subject, the assaulter, the victim, and three confederates; one female and two males. As was predicted males intervened significantly more than females. It is probable that the females in this study diffused the responsibility for intervention to the two male confederates since the most appropriate intervention in this situation was direct. Contrary to the second prediction, males did not intervene more when the victim was a female, but, actually intervened less often. The least amount of intervention occurred with a male assaulter and a female victim. Borofsky et al. (1971) concluded that males failed to intervene "because they were deriving some kind of vicarious sexual and/or hostile gratification from seeing a man injure a woman" (p.317):

In 1976, Shotland and Straw explained Borofsky's results by suggesting that bystanders assume a man and a woman that are fighting have a close relationship and will be unlikely to interfere in a "lovers quarrel". In their study subjects overheard a quarrel between a man and a woman which resulted in the physical assault of the woman. In a stranger condition the woman screamed, "I don't know you!" and in the married condition, "I don't know why I ever married you!" As was hypothesized, intervention was significantly more frequent when subjects were led to believe the attacker and victim were strangers (65\%) rather than married (198). It's possible the subjects in 
Borofsky's study assumed a relationship between the female and male and didn't want to interfere in the quarrel.

Therefore, it seems not only is it important to understand bystander and subject characteristics, but victim characteristics are also significant. According to the data, uncontrollable aspects of an individual (sex, race and birthmarks) may determine whether help is given in an emergency.

\section{Characteristics of the Emergency}

Characteristics of the emergency are noteworthy in the interpretation process. For example, if the emergency is ambiguous people can not be sure it is an emergency. The study of these characteristics is important in determining what emergency variables most reliably predict whether an individual will or will not help.

Clark and word (1974) manipulated the ambiguity of an emergency situation and found help depended solely upon ambiguity. Help was given significantly more in a non-ambiguous and moderately ambiguous situation than in a highly ambiguous situation; 888,758 and 138 , respectively. These results support Darley and Latanés model of helping since an ambiguous event may lead to a misinterpretation of the situation thus resulting in less help.

Very few studies have differentiated between internal (emergency threatens subject) and external emergencies (a third parter is in danger). However, Ross (1971) and Ross and Braband (1973) did manipulate the emergency in this way. In both studies no main effect was found for type of emergency. Whether the emergency was a threat to the subject; smoke filled room, or a threat to a third party; workman in distress, there was no difference-in subjects' response 
rates. Most important in these studies was the presence of a depen-. dent other bystander (child or blind) which did have a significant effect upon helping. The social influence process appears to be very powerful regardless of who the fellow bystanders are.

The location of the emergency in relation to the witness also is an important variable in the prediction of helping behavior. The greater distance between an individual and the emergency the more likely a subject will diffuse responsibility to those closer. Also if "escape" from the area of the emergency is not possible, intervention is likely to increase. Staub and Baer (1974) staged an emergency either in the direct path of a bystander or on the opposite side of the street. The results show that witnesses who can easily escape from an emergency are significantly less likely to help than when the emergency occurs in their direct path with no escape; $27 \%$ vs $78 \%$, respectively.

As has been shown, characteristics of the emergency are important determinants of helping behavior. One can conclude that generally if indivuduals see a nonambiguous emergency occur in their direct path they are likely to help the distressed person. Increases in Helping Behavior

Much of the research reviewed thus far has dealt with the inhibitors of helping behavior, such as diffusion of responsibility, nonreactive bystanders, etc. However, some investigators have tried to increase helping behaviors with the use of reactive bystanders (Smith, Vanderbilt \& Callen, 1972), children or bilind dependent others (Ross, 1971; Ross \& Braband, 1973), and focusing responsibility (Staub, 1970a) to name just a few. However, in the "real world" 
bystanders may not overtly react when witnessing an emergency and the variables which can be manipulated in the laboratory are often not present when an actual emergency occurs. Hammersla (Note 3) and Beaman, Barnes, Klentz and McQuirk (1978) have attempted to increase helping behavior by making subjects aware of the circumstances and inhibitors of an emergency situation.

Hammersla (Note 3) had subjects either role play or observe an emergency and found these subjects subsequently helped significantly more than control subjects with no previous experience in an emergency situation.

Beaman et al. (1978) informed subjects of the inhibiting influences in an emergency situation. Diffusion of responsibility, social comparison and evaluation apprehension were explained by two methods; eithex by lecture or film. Another group of subjects received a control lecture on emotions and obesity and a control group was included which received no lecture or film. Subjects then witnessed an emergency ( a man slumped in a hallway) in the presence of a nonreactive bystander. Subjects who received-emergency relevant information, helping film and helping lecture, intervened significantly more than did the control and emotion lecture groups. Combining the two control groups and the two experimental groups yielded a $25 \%$ helping rate for control subjects, while subjects receiving emergency relevant information helped 42.58 of the time. These studies show that experience in an emergency situation or information about the inhibitors of helping effect the subsequent helping response rate of individuals.

Somewhat conflicting results have been found by Bickman (1975). 
In this study a mass-media campaign (signs, handbills, ads in newspapers, editorials) was undertaken to increase bystander intervention in a shoplifting which took place at the University bookstore. The campaign consisted of information on how and why to report a shoplifting and attempted to change students' attitudes toward the bookstore. Although this campaign did alter behavorial intentions, no increase in actual intervention behavior was found. This was true whether the shoplifter was a student or an older adult. Perhaps an important difference in these two studies was the type of information given to the subjects. In one study (Beaman et al., 1978) subjects were informed as to what social factors inhibit a helping response, whereas in the other (Bickman, 1975) subjects were given information on how and why to intervene.

As has been shown throughout this review, prediction of an individual's behavior in an emergency situation is quite complicated. Characteristics of the victim, the individual, other bystanders and of the emergency itself all are important factors which must be considered. Also when reading the literature, it is important to keep in mind the severity of the emergency, whether the emergency is internal or external, the type of helping response (direct or reportorial) and whether the dependent measure is dichotomous (help or no help), a continuum of responses, or the speed of the response. It is difficult to compare studies which, for example, investigate subject characteristics but use emergencies differing in severity and requiring different types of responses.

Perhaps then the witnesses of the murder of a young woman in 1964 were not apathetic or gratifying sadistic impulses, but instead 
victims of very strong situational influences. There is hope in the fact tht knowledge of the inhibitors of helping behavior will increase the liklihood an individual will receive help in an emergency. The old adage of "safety in numbers" although widely believed, has not held up under scientific investigation.

SHOPLIFTING RESEARCH

Individuals often fail to take socially responsible action when an emergency occurs. A number of studies have also found a failure to act in a socially responsible way after a person observes a criminal act. Namely, the reporting rate of crimes has been shown to be surprisingly low. Latané and Darley (1970), not long after developing their helping model, began investigating the factors which inhibit bystanders reporting a crime. A study was conducted in which either one or two subjects witnessed a confederate steal money from an envelope left on the experimenter's desk (Latané \& Elman, 1970). The results were consistent with the results of the emergency helping studies. Reporting of the theft occurred more often when only one subject witnessed it, than when two subjects were present.

A second study conducted in the field resulted in similar findings (Latané \& Darley, 1970). In this study either one or two robbers stole a case of beer from a liquor store in the presence of one or two bystanders. The number of thieves made no difference on the liklihood that the theft would be reported, but the number of bystanders that witnessed the robbery did. Again, subjects were more likely to report the crime if they witnessed it alone.

Subsequent studies have been conducted which examined the char- 
acteristics of the thief and the bystanders. Most often the type of crime chosen for study was shoplifting. There are several reasons for this selection (Bickman \& Rosenbaum, 1977). Shoplifting is relatively easy to stage, there is little or no danger to the "criminal" will be physically assaulted by an over zealous bystander and finally shoplifting is a major social problem.

Gelfand, Hartmen, Walder and Page (1973) had a young woman dressed conventionally or in hippie garb shoplift in a high-income suburban area or in a lower-income central-city area. They found that although subjects reported liking the conventionally dressed woman significantly more than did subjects who saw her dressed as a hippie, the different garb conditions had no effect on the reporting. of the theft. The location of the store was also unrelated to the reporting rate. They did find, however, that male shoppers reported the shoplifting twice as often as female shoppers and persons from small towns or rural areas reported the theft significantly more than persons from large cities (population greater than 100,000).

Dertke, Penner and Ulrich (1974) investigated reporting of a shoplifter as a function of the thief's sex and race. No main effects for race or sex were found in the reporting of the shoplifter. However the black male shoplifter was reported significantly more often than the white male thief $(23.5 \%$ vs $6.6 \%$, respectively). This was due primarily to the large reporting rate of the black male by female subjects. Dertke et al. found, contrary to Gelfand et al. (1973), that females reported the thefts significantly more often than males. Another conflicting result of Gelfand et al. was found by Steffensmeier and Terry (1976). They also examined the effect of 
dress style (hippie vs straight) on the reporting of a male or female shoplifter. Although sex of the shoplifter had no signficant effect, the style of dress did significantly influence reporting rate; the hippie dressed thief was reported significantly more often.

Darley and Latané's decision model of intervention has been extended by a number of investigators to the area of crime reporting. Bickman and Rosenbaum (1977) reasoned before a bystander will report a crime he/she must notice it, interpret it as a crime, take responsibility to act and decide how to act.

Using this model investigators have attempted to study the effect of making the bystander responsible to act (Moriarty, 1975; Shaffer, Rogel \& Hendrick, 1975), defining the situation as a crime (Bickman \& Green, 1977; Bickman \& Rosenbaum, 1977) and informing subjects how to report the crime (Bickman \& Green, 1977; Bickman, 1975).

Moriarty (1975) increased the responsibility of subjects to intervene and stop a theft on the beach by having subjects commit themselves to the victim in advance. Subjects who were asked to watch the victims belongings in their absense were more likely to pursue and stop the thief. than subjects who had not committed themselves (95\% vs 20\%, respectively). Shaffer, Rogel and Hendrick (1975) found similar results when subjects were asked to watch a confederate's belongings in the library.

Bickman and Green (1977) designed a situation wherein a confederate influenced subjects to notice a theft, interpret it as such and either encourage or discourage reporting. As was hypothesized, those encouraged to report did so $72 \%$ of the time while only $32 \%$ of those 
who were discouraged from reporting actually did so. In a second study these results were replicated and a third group was added which received a non-crime interpretation of the theft. Interpreting the event as a non-crime prroduced a similar level of reporting as the discouraging manipulation.

Bickman and Green (1977) and Bickman (1975) attempted to increase the reporting of shoplifting with the use of posters and mass-media campaign, respectively. They hypothesized that the presence of posters providing information on how to report a shoplifting would influence one's decision to report and thus increase that behavior. Bickman and Green found a significant change in the percentage of subjects who strongly agreed that the store needs customers' help in controlling shoplifting. However, there was no difference in the actual reporting of shoplifting between the before-sign and during-sign conditions.

Bickman (1975) tried to increase the reporting of a shoplifting in the university bookstore through a mass-media campaign. Handbills were passed out, signs were posted, ads were placed in the campus newspaper describing how and why to report a shoplifting. Included in the campaign was an attempt to change students' attitudes toward the bookstore. That is, students were told: "The University store is part of the university community to which students have a responsibility," and "Shoplifting has an effect on your Campus center fee by reducing the income of the store which goes into the Campus Center operating fund." Although the campaign sucessfully communicated the information and significantly increased the behavioral intentions to report shoplifters, there was no increase in the actual reeporting. 
Hyman and Sheatsley (1947) propose some guidelines for a successful information campaign. These are; 1 . The audience must be exposed to and absorb the information; and 2. The material must be geared to the public's interests. Perhaps Bickman's campaign was not successful in reaching all the students and those that did get the information were not very interested.

As was reported, Bickman (1975) did find a change in attitudes toward the bookstore as a result of the campaign. However, the relationship between attitudes and behavior is at best tenuous. Festinger (1964) reported three studies which investigated the attitude change-behavior relation. The conclusion drawn from these studies was that attitude change does not lead to a behavior change. Festinger suggested that when attitudes are changed by means of a persuasive communication, the change is unstable and will disappear unless an environmental or behavioral change is produced which supports the new attitude.

Rokeach and Kliejunas (1972) suggested that one can increase prediction of behavior from attitudes if one takes into account both the attitude toward the object in question and the attitude toward the situation. Ajzen and Fishbein (1977) stated that low correspondence between attitudes and behavior which had been found in many studies was attributable to the low correspondence of the elements of the attitude (target, action) as compared to the elements of the behavior. In their review of the literature it was found for those studies in which the attitude and behavior did not involve the same target and action, there was a nonsignificant relationship between the attitude and behavior in 968 of the studies. However, in those 
studies which had a high correspondence between the elements of an attitude and the behavior, 808 found highly significant relationships. Therefore if the attitude and the behavior have the same target and linvolve the same action a high correspondence should result. Although Bickman's (1975) subjects had a positive attitude toward the bookstore, unless they also had the attitude they were personally responsible to report the crime they probably would not report the shoplifter. 
Chapter 2

PROPOSED RESEARCH

As was mentioned earlier, Beaman et al. (1978) succeeded in increasing intervention in an emergency helping situation., This was done by lecturing to students on the factors which inhibit an individual from helping. The approach was strictly informational and no attempt was made to change attitudes, although an attitude change may have occurred. Rather the experimenters attempted to increase ones'understanding of the forces which influence behavior when an emergency is observed.

The present study was an attempt to reconcile the differing results found by Bickman (1975) and Beaman et al. (1978). Although both studies disseminated information to a student population, only Beaman et al. was successful in increasing the desired behavior, that of helping in an emergency situation (their results were produced in two seperate studies).

The type of information transmitted was one of the main differences between the two studies. Bickman's campaign dealt with how and why to report a shoplifting with the inclusion of information about the bookstore to change students' attitudes toward it. Beaman et al., however, informed students of the social-psychological factors which inhibit an individual from helping. Therefore, three informational conditions were included in the present study. These were an Information group to conceptually replicate Bickman's study, an 
Inhibitors group to replicate Beaman et al. and an InformationInhibitors group which included a combination of the information disseminated in both previous studies. It was hypothesized that the Information group would not differ from a control group which received irrelevant (to shoplifting) information. An increase in reporting of shoplifting was predicted for the Inhibitors group and the largest reporting was expected in the Information-Inhibitors group. Another important difference between the Beaman et al. and Bickman studies was the method by which the information was disseminated. i.e. lecture or mass-media campaign. Therefore to determine any differential effects resulting from the method of exposure, half of each group received the information via lecture and the other half received the information via a written format (to approximate the mass-media campaign). It was hypothesized the material presented in lecture form would be more closely attended, to and therefore would increase the reporting of shoplifting over the effect for presenting material in written form. The four groups receiving written information were expected to differ in reporting rates in the same order as the four lecture groups. 


\section{Chapter 3}

METHOD

\section{Subjects and Brief Overview}

The subjects were 171 introductory psychology students (72 males, 99 females). Each attended one of eight preliminary sessions in which he/she was exposed to differing information concerning shoplifting or obesity, in either lecture or written form. Other students not randomly selected for one of the eight major experimental or control groups still participated in a pre and post-attitude assessment. These persons comprised a ninth group that furnished attitude data for comparison purposes. The eight preliminary sessions contained the manipulation of the independent variables. Each subject participated in a second interaction approximately two weeks later (mean $=16$ days, range $=7$ to 33 days). At that time subjects observed a staged shoplifting. The second sessions were conducted at the university bookstore and were made to appear totally unrelated to the first session by having a separate experimenter contact subjects by phone to participate in a marketing research study which would be conducted at the bookstore.

General Procedure

In the eight preliminary sessions, subjects were informed they would be evaluating material being developed for use in a mass-media campaign. Four of these groups received the information in lecture form and four received the information, in slightly abbreviated form, 
presented in, a written format to approximate mass-média type exposure. The lecture groups 1 istened to a lecture approximately 30 minutes long while the mass-media groups were asked to carefully read a pamphlet and handbill and also examine a poster, which required about $30 \mathrm{~min}$ utes.

Information groups. The subjects in these groups were exposed to information consisting of how to report and why one should report incidents of shoplifting. This included the information used by Bickman (1975) concerning the students' relationship with the bookstore, and was designed as a conceptual replication of his mass-media campaign type study.

Inhibitors groups. The subjects in these groups were informed concerning the social-psychological factors that operate on persons that result in failure to report shoplifting. Some of the factors presented were diffusion of responsibility, reluctance to become involved, evaluation apprehension etc.. These conditions were designed as a conceptual replication of the Beaman et al. (1978) study with emergency helping behavior.

Information and inbibitors groups. The subjects in these groups were exposed to a combination of the material presented in the previous two groups. It was expected that these subjects would change their attitude toward the bookstore as well as gain a better understanding of the social-psychological forces which control their behavior.

Control groups. The subjects in these groups were presented material on the social psychology topic of obesity and emotion, which was similar in interest level to the material on shoplifting. These 
groups were designed to control for the number of experimental participations, exposure to social psychology material and exposure to a professor.

Check on the Manipulation

To ascertain whether the subjects had adequately been exposed to the manipulations a questionnaire was completed by all subjects at the end of their first session. Questions were included concerning specific content and measures of interest level of the material. Of course, it was critical that subjects heard (read) and processed the relevant information or else no effects for exposure would be expected later. The data from the questionnaire results could also be analysed later to see if subjects who reported the shoplifter differed in their responses from those who did not report the shoplifter. Second Session and Dependent Variables

Subjects who had participated in the first session were contacted by phone and asked to participate in a marketing research study. They were met in the psychology building and were told the study was being conducted at the university bookstore. While the experimenter and subject walked to the bookstore, the experimenter explained what marketing research was and that a display was set up in the bookstore with items which the subject would be asked to evaluate. Subjects were escorted to a back section of the bookstore and were requested to wait outside a backroom while the experimenter made sure the display was set up properly. It was emphasized the subject should not wander around and look at the merchandise so their evaluation would not be influenced by these distractions later. This procedure actually was intended to keep the subject in a position to easily observe the shop- 
lifting.

Shortly after the experimenter left, a female shoplifter (confederate) walked up and stood approximately five feet from the subject apparently looking for an item. However, if the shoplifter noticed a bystander in the area she moved close to where the person was standing. In nearly every case the bystander moved out of the area. This procedure was based upon the expected consequence of violating ones personal space (Hayduk, 1978). The experimenter, who stood behind a door containing a small one-way mirror signaled when the subject was looking at the shoplifter and when no bystanders were in the area. The shoplifter placed a combination lock in her purse and walked approximately 12 feet away and started to browse through a rack of tee shirts, keeping her back to the subject. A clerk (confederate) was positioned 15 feet behind the subject and appeared to be taking inventory of some stock. After two minutes, if the subject had not reported the shoplifting, the experimenter returned and took the subject into the backroom. In cases where one or more bystanders were in the area and did not move completely out of the area when their personal space was violated no shoplifting was staged until the area was clear. If after 10 minutes the bystanders still remained the experimenter returned to the subject and took him/her into the backroom.

Subjects were considered to have intervened if they told the shoplifter to put the item back, reported the shoplifting to any store employee or reported it to the fake clerk or experimenter. If any of these responses occurred the time in seconds that had elasped was recorded. The suspiciousness of the subject was then assessed using a 
funnel approach. Debriefing was performed and any questions answered. All subjects were made to feel that their participation had been very helpful. Regardless of their behavior they were made to feel that their actions were normal and acceptable. In the case of non-reporters this was done by emphasizing the low reporting rates in general (about $48)$.

\section{Attitude Questionnaire}

At the beginning and end of the quarter all introductory psychology students were asked to complete an attitude questionnaire on cheating and shoplifting. Cheating questions were included to partially disguise the purpose of the questionnaire. Students were told the questionnaire was concerned with problems common to college students. These questionnaires were completed in the discussion sections of their introductory class and were not related to the other parts of the study. Any attitude change which occurred for any or all groups, reporters or non-reporters could be assessed. 
Chapter 4

RESULTS

Overall 20.5\% of the subjects reported the shoplifting. As was mentioned earlier subjects could report the theft to any store employee, tell. the shoplifter to put the item back, confirm the theft by asking a bystander or report it to the experimenter. No differences were found among the groups for the method of reporting. For those subjects that reported the shoplifting, 32\% informed the clerk (confederate), 41\% talked to the shoplifter, $26.5 \%$ told the experimenter and $3 \%$ talked to a bystander:

Check on the Manipulations

After the preliminary sessions in which the information dissemination occurred subjects rated the lectures or mass-media materials on interest level, clarity of presentation, enthusiasm of presentation and preparation. No differential effect by group was found for interest level or clarity of presentation. There was a significant group effect for enthusiasm and preparation, $\underline{F}(7,163)=5.29$, p<.01; $\underline{F}(7,163)=2.88, \underline{p}<.01$, respectively. Newman-Keuls post-hoc tests indicated that this was primarily due to better ratings of lectures than mass-media written materials. To determine if enthusiasm, preparation, interest level or clarity of presentation had any effect upon reporting four ANOVAs (ratings by report/not report) were performed. None of these indicated that ratings were related to the reporting of shoplifting. Hence any subsequent differences discussed 
should not be attributed to these variables.

Subjects also answered questions concerning the specific content covered in the lectures or mass-media materials. No differences were found in their ability to recall the material as a function of whether the material was verbally presented or read by the subject. Both the lecture format and the mass-media format were effective in disseminating the information for each condition. The percentage of correct responses to the question asking them to list four major points covered in the presentations were all about $70 \%$

\section{Major Dependent Variables}

A significant group by report effect was found. This effect was significant with and without suspicious subjects, $\underline{x}^{2}(7)=19.8, \underline{p}<.01$; $\underline{x}^{2}(7)=14.2, \underline{p}<.05$, respectively. Therefore, further analyses will include all subjects.

It was hypothesized the groups which were exposed to shoplifting information via lecture would report the shoplifting more than the groups which received the information in a mass-media format (posters, handbills, pamphlets). The results supported this contention, $\underline{z}=2.6$, $\underline{p}<.005$.

Both control groups (those presented information concerning obesity and emotions by lecture or mass-media material) had nearly zero percent reporting rates; only one person reported. Thus these control groups were combined for subsequent analyses and will be referred to as the control group. Each type of information given via lecture increased the reporting rates, (Information, $\underline{z}=3.12, \underline{p}<01$.; Inhibitors, $\underline{z}=2.28, \underline{p}(.01 ;$ Information-Inhibitors, $\underline{z}=15.9, \underline{\mathrm{p}}(.001)$. For those groups which received the information via written materials 
the Information and Inhibitors groups both differed from the control group, $\underline{z}=1.82, \underline{p}<.03 ; \underline{z}=1.73, \underline{p}<.04$, respectively. The difference in reporting rate for the Information-Inhibitors group was marginally significant, $\underline{z}=1.55, \underline{p}<.06$. It appears that the experimental groups, which received various information about reporting shoplifting, were superior in reporting the staged shoplifting later.

Also of interist was what type of information was most influential. As shown in Table 2 differential reporting rates were found over the lecture groups and the mass-media groups. However, these differences between groups with the same presentation format (lecture or mass-media) were not statistically significant. That is none of

Insert Table 2 about here

the lecture groups differed fxom each other and none of the massmedia groups differed from each other. Although, as mentioned, there was an overall superiority in reporting rates for lecture groups; only one group showed this difference when comparing the same information conditions across presentation formats. That is InformationInhibitors lecture group reported the crime more frequently than the Information-Inhibitors mass-media group, $\underline{z}=2.33, \underline{p}<.01$.

A second dependent variable was the speed with which the subject responded to the crime. Latency scores were converted to speed scores (1/time X 100), and an ANOVA was performed for those subjects who did report in the eight conditions. The type of information received had no effect upon the speed of response, $E(5,28)<1.0$. The method by which the information was disseminated also had no effect upon the 
speed of responses, $\underline{F}(1,33)<1.0$.

Overall, there was a $21.6 \%$ suspicion rate. Chi-Square analyses indicated the distribution was not independent of condition assignment, $\underline{x}^{2}(7)=15.5, \underline{p}<.03$. Also, suspicious subjects were more likely to report the shoplifting than were nonsuspicious subjects, $45.9 \%$ vs. $13.4 \%, \underline{z}=4.33, \underline{p}<.001$. Table 3 presents the percentage of reporters for nonsuspicious subjects. Removing the 37 suspicious subjects from the analyses did not alter any of the conclusions stated above except those concerning the mass-media groups. These groups no longer reported at a rate greater than the controls when each experimental mass-media group was considered seperately or when they were combined for analyses. No other dependent variables were effected by the suspiciousness of the subject, since all other measures were taken at other times seemingly unrelated to witnessing the shoplifter in the bookstore.

Insert Table 3 about here

Subjects of both sexes were run, hence sex differences in the reporting of the shoplifter (female) could be examined. Overal1, 19\% of the males reported the shoplifter and $21 \%$ of the females did so. These percentages were not statistically different. Attitude Questionnaire

A shoplifting attitude questionnaire was given at the beginning and end of the quarter to all introductory psychology students. At the beginning of the quarter 244 students filled out the questionnaire, 139 of which later participated in the experiment (others who 
participated were absent on the day the questionnaire was given). The attitudes as measured by the pre-study questionnaire were not different as a function of subsequent group membership. Almost all students felt shoplifting was wrong $(99 \%)$. When asked if they thought shoplifting was a serious problem, $70 \%$ felt it was very serious, $28 \%$ felt it was moderately serious and $2 \%$ felt it was not serious at al1. Students were also asked if it was ever justifiable to shoplift. Eighty-nine percent agreed it was never justifiable, $8 \%$ thought it was justifiable if the person had no money and $3 \%$ thought it was justifiable if prices were too high. No one felt shoplifting was always justifiable. Ninety-four percent of the sutdents felt shoplifting affects prices. When asked what they would do if they saw someone they did not know shoplift, $47 \%$ said they would either report it to the nearest clerk or talk to the shoplifter. Fifty percent said they would ignore it. However, when asked what one should do if a stranger is seen shoplifting, $86 \%$ said it should be reported to the clerk or one should talk to the shoplifter. Only $13 \%$ thought it should be ignored.

At the end of the quarter, this same questionnaire was again given to the psychology class. Of those people that witnessed the shoplifting, 129 completed the questionnaire, and 106 people that did not participate in the study completed the questionnaire. For. those people that were not in the study there was no difference in their attitudes towards shoplifting as measured approximately eight weeks after they first filled out the questionnaire. They still felt shoplifting was wrong and that it affected prices. Again, when 
asked what they would do if they saw a stanger shoplift, $48 \%$ thought they would report it to a clerk or talk to the shoplifter, while $50 \%$ thought they would ignore it. For those people that did participate in the experiment, two interesting changes occurred. When asked what they would do if they saw a stranger shoplift, 73: thought they would now report it to a clerk or talk to the shoplifter. Only $27 \%$ thought they would ignore it. This change in attitude (prestudy, $50 \%$ would ignore it) was significant, $\underline{z}=2.57, \underline{p} \times 005$. Also, for those subjects in the study an interesting change occurred when asked if shoplifting affects prices. For those groups which received information concerning shoplifting, before the study, 53.8\% felt prices were affected a great deal by shoplifting. After the study, $74.3 \%$ felt prices were affected a great deal. Originally, 41. 2\% of the subjects in the control groups, which only witnessed a shoplifting, felt prices were affected a great deal. After the study, 61.5\% felt prices were affected. For those people not in the study, no change in attitude was found (49.5\% vs. $54.7 \%$, pre and post). It appears that just being in a study in which shoplifting is being investigated is sufficient to change subjects' attitudes. 
Chapter 5

DISCUSSION

As was hypothesized the groups which received the shoplifting relevant information in lecture form reported a staged shoplifting significantly more often than groups which received the information through mass-media campaign materials. The lecture groups were presented the information accompanied by examples of relevant research to document the materials. Even though the mass-media groups did not differ from lecture groups on their comprehension of the material or their ratings of its interest level a difference in reporting rates resulted. One possible explanation might be that material presented verbally is bettex retained over time. Thus, two weeks later when confronted with a shoplifting the information was recalled and used. Also since the lecturer was not blind to the hypotheses of the study he may have inadvertently revealed the hypotheses to the lecture subjects. However, the percentage of lecture group subjects who were suspicious during the second session (26.8\%) did not differ from the percentage for mass-media groups (21\%). Hence it doesn't appear that inadvertant communication by the lecturer was a problem.

Another possible reason for the higher rates in the lecture groups may be related to the examples of research detailed in the lectures, but not in the pamphlets. These details were not included in the pamphlets because such lengthy discussion is not common in massmedia materials. The purpose of these written materials was to con- 
ceptually replicate Bickman's (1975) study, which used even briefer materials. It is possible that the research presented in lectures gave the students examples of the appropriate behavior, which facilitated their reporting later.

Information concerning how and why to report a shoplifting as well as information concerning what inhibits one from reporting a shoplifting were both found to increase the desired behavior. This study attempted to reconcile the differing results found by Bickman (1975) and Beaman, Barnes, Klentz and McQuirk (1978). Bickman informed subjects through a mass-media campaign how and why one should report a shoplifting. However, he produced no increases in reporting rates. Beaman et al. lectured to subjects informing them of the socialpsychological factors which inhibit helping in an emergency. Subjects who received this information were more likely to offer aid to a man slumped in a hallway than were subjects who had not received the information. Based upon the results reported in those two studies it was hypothesized in the present study that the Information group would not differ from a control group while the Inhibitors group would show an increase in renorting rates. The actual results indicated that both groups were successful in increasing reporting.

One possible explanation for the high reporting rates in the mass-media groups concerns the technique used to present the written materials. Subjects in the present study, unlike those in Bickman's, were instructed to read the materials carefully in order to later evaluate it. This "careful" reading of the material as opposed to glancing at a poster, or handbill may have created a stronger manipulation in the present study. As was stated earlier, the most 
important criteria for a successful information campaign is that the audience is exposed to and absorbs the information (Hyman \& Sheatsley, 1947). If the information is not "absorbed" it cannot possibly affect behavior.

The type of information disseminated in the Inhibitors group was found to increase subsequent intervention in an emergency (Beaman et al., 1978). In the present study this information again had the expected effect when extended to reporting of shoplifting. Unexpectedly the reporting rates were not greater than those for the Information groups as was hypothesized. Huston, Geis, Wright and Garrett (1976) found that intervention in an emergency is prompted out of concern for the victim and situational factors; whereas intervention in a crime is more closely related to attitudes toward crime, criminals, and the police. They report criminal interveners characteristically have sympathy for and support law enforcement. Therefore attitudes such as these may also be an important factor when intervening in a criminal act. Although these results were based upon interviews with "Good Samaritans" they may be tentatively applied to the present data. Perhaps the Inhibitors group did not have a more pronounced effect in increasing the reporting of shoplifting because the type of information disseminated was primarily concerned with situational factors which inhibit intervention. This type of information affectshelping in an emergency more intensely than it does intervention in a crime. Further research must be completed before any definite conclusions can be stated.

The Information-Inhibitors group which was a combination of the information presented in the other experimental groups was also suc- 
cessful in increasing the reporting of a shoplifter. It was hypothesized that the interaction of these types of information would produce the largest increase in reporting rates. Both a knowledge of the social-psychological factors that inhibit one's behavior and one's attitude toward the party or institution involved in the emergency or crime may play a role in controlling one's behavior. This contention is partially supported in that the Information-Inhibitors group was marginally different from the Inhibitors group, $\underline{z}=1.53$, $\underline{p}$ <.06. The only difference between these two groups was the attitude change information presented to the Information-Inhibitors group. (The Information and the Information-Inhibitors groups did not differ, $\underline{z}=.92, \underline{p}<.18$.

Behavior is usually considered to be a function of both the situation and the person's characteristics. Included as characteristics are persons' attitudes. It would appear in emergency helping most people have an attitude that it is good to help a victim, although situational factors may inhibit this response. Hence, understanding forces that operate on one that inhibit helping may allow one to overcome these forces. In emergencies it is often the case that the bystander is trying to process information about a rare and ambiguous event to determine not only what it is but what should be done. For example, has someone already helped? Or if others aren't concerned maybe it really isn't serious. However, when someone witnesses a crime such as shoplifting, it may be that the bystander's attitude toward the "victim" (a store, for example) may not be positive. To the extent that the attitude is negative (prices are too high therefore, the store deserves to be stolen from) then one would 
not expect reporting; even if a bystander was aware of social-psychological forces that operate on him which inhibit reporting. Likewise, if one's "most hated enemy" was a victim in an emergency one might not expect help to be rendered. Perhaps, both an attitude component and a knowledge of social-psychological forces are influential in determining behavior. The specific type of emergency or crime will be differentially responded to as a function of general attitudes, an individual's specific attitude and knowledge of the situational forces operating. Speed of Response

The speed with which subjects reported the shoplifting was not different for any of the groups. The mean response time was 54.7 seconds and ranged from 4 seconds to 120 seconds (the total amount of time ailowed). Although it was not hypothesized, one might expect those groups that received information on how to report the shoplifting would report fastest. For these subjects once they have decided to report, they would already have the knowledge about possible methods. However, this was not the case.

Method of Reporting

Also of interest, is the method of reporting the shoplifting. Although, no significant differences were found among the groups for the method of reporting, $\underline{x}^{2}(2)=4.22, \underline{p}<.13$, in the Inhibitors group not one subject reported to the clerk. However, $42 \%$ of the reporters in the Information group and $40 \%$ of the reporters in the Information-Inhibitors group chose to talk directly to the clerk. Perhaps, since the Inhibitor subjects were aware of the inhibiting factor, diffusion of responsibility, they then overcame this by taking 
direct action and did not diffuse responsibility to the clerk. Additionally, the Inhibitor group had not been given specific information on how to respond (such as reporting to the clerk) and so chose the most direct method of intervention.

\section{Suspicious Subjects}

Overall, $21.6 \%$ of the subjects that witnessed the shoplifting later reported they were suspicious during the incident. Previous researchers have argued that subjects may report being suspicious even though they were not, so they don't appear foolish or to explain their nonintervention. In the present study, subjects were more likely to claim to be suspicious if they were in the groups previously given information concerning shoplifting. Therefore, the distribution of suspicious subjects may be problematic in interpreting the data. When the suspicious subjects are removed, the lecture groups still report at levels significantly greater than both the control groups and the mass-media groups. However, mass-media groups no longer reported significantly more than the control groups. As was mentioned earlier, subjects in the mass-media groups were asked to carefully read the material and based on questions asked immediately after the preliminary session, it appeared lecture and mass-media groups comprehended the material equally well. Assuming these questions tapped knowledge relevant to one's reporting shoplifting, it is not obvious why the mass-media groups did not report more.

Once again, the Information-Inhibitors group had the largest percentage of subjects reporting. Although, as before, it was not significantly higher than the other experimental lecture groups. 
Although the suspicious subjects make the interpretation of the data more difficult, it must be remembered that subjects were suspicious that the staged shoplifting might not be real, but were not suspicious that the first session they participated in was related to the second. Hence the data are not particularly confounded with demand characteristics allowing subjects to guess the hypothesis. The suspicious subjects who reported share a very important attribute with the nonsuspicious subjects who also reported. Both made a decision to perform an unusual behavior that of reporting a person who may have been an actual shoplifter. There was enough ambiguity in the situation for most subjects so that even though they thought it might be a staged shoplifting they went ahead and acted. Thus to discard suspicious subjects and base the analyses totally on the remaining subjects results in a loss of information. Sex Differences

In the present study, no differences in reporting were found for males and females. Mixed results have been reported in the literature. Gelfand, Hartmen, Walder and Page (1973) found males reported the shoplifting twice as often as females. However, Dertke, Penner and Ulrich (1974) found females reported the shoplifting significantly more than males. A number of studies fail to report any differences between males and females (Bickman, 1975; Moriarty, 1975; Bickman \& Green, 1977). Therefore, it appears the effect of sex on reporting of a shoplifter, if any, has not been reliably determined. Further research must be completed before any conclusions are stated. Possible Confounding Variables

The mean number of days between the preliminary session and the 
staged shoplifting was 16 (range $=7$ to 33 ). Three correlation coefficients were computed to examine the relationship between the subjects' self-report of suspiciousness of the clerk, the shoplifter, and the experiment in general with the number of days between sessions. These were $.11, .10$ and .04 respectively. All were nonsignificant. A Chi-square was also computed to test the independence of the number of days between sessions and whether the subject reported the shoplifter. This was also nonsignificant. Thus the number of days between the first session in which the relevant information was disseminated and the shoplifting had no effect upon the results of the study.

Another possible confound might have been the time of day the shoplifting occurred. While the study was in progress, it appeared the morning was the busiest time of day in the bookstore. It is possible that subjects run during these hours might have been distracted and therefore not report the shoplifting as frequently. However, reporting rates were independent of the time of day during which the subject was run, $x^{2}(2)=1.08$, ns.

Many different confederates assisted in the execution of the study. Chi-square analyses conducted to see if there were any relationships between particular confederates when they enacted specific roles (shoplifter, clerk or experimenter) demonstrated that these variables were independent of the results. Attitude toward Shoplifting

Attitudes towards shoplifting were also measured in the present study. The results show that students have quite negative attitudes towards shoplifting. Ninety-nine percent of the students felt shop- 
lifting was wrong, $89 \%$ thought it was never justifiable to shoplift and only $2 \%$ felt it was not a serious problem.

When asked what they would do if they saw someone they did not know shoplift, before the study began $47 \%$ said they would either report it to the nearest clerk or,talk to the shoplifter. On the post-study questionnaire 73\% said they would report it (p<.005). Bickman (1975) interviewed students in the bookstore and found that before his mass-media campaign began $15 \%$ of those interviewed said they would report the shoplifter to a clerk or talk to the shoplifter. After the campaign, this figure increased to $35 \%$. One is struck by the large initial differences in Bickman's study and the present one (15\% vs. $47 \%$, respectively). There are two possible explanations for this. It has been found rural shoppers report shoplifters significantly more than urban shoppers (Gelfand et al., 1973). Since Bickman's study took place in a large community and the present study was conducted in a small community, perhaps the initial difference is due to this factor.

A second explanation deals with the manner in which the data were collected. Bickman's subjects were personally interviewed in the bookstore whereas in the present study, subjects completed a written questionnaire. Perhaps, being in the actual situation allows one to more accurately predict one's behavior. The environmental cues of actually being in a store may allow one to "role play" more correctly.

This study was successful in increasing the reporting of a shoplifting, however, a number of questions remain which might be investigated. Future research should examine the differences between 
the lecture and mass-media groups (use of examples, verbal vs. written, retention of material, etc.) to determine the cause of the greater reporting rates in the lecture groups. Also of interest is the relative importance of attitudes and the knowledge of inhibiting situational factors in the reporting of a crime as compared to intervention in an emergency. 


\section{REFERENCE NOTES}

1. Beaman, A. I. Effects of evaluation apprehension and social comparison on emergency helping behavior. Unpublished manuscript, University of Montana, 1972.

2. Ruch, L. O., Newton, R. R., \& Kough, A. L. Sexual composition of the bystander group and intervention in an emergency. Paper presented at the meeting of the Pacific Sociological Association, Sacramento, April, 1977.

3. Hammersla, J. Behavioral and attitudinal effects of participation as a victim or bystander in a laboratory intervention study. Unpublished doctoral dissertation, University of Washington, 1973. 


\section{REFERENCES}

Ajzen, I., \& Fishbein, M. Attitude behavior relations: A theoretical analysis and review of empicrical research. Psychological Bulletin, $1977,84,888-918$.

Annis, L. V. Emergency helping and religious behavior. Psychological Reports, 1976, 39, 151-158.

Ashton, N. L.; \& Severy, L. J. Arousal and costs in bystander intervention. Personality and Social Psychology Bulletin, 1976, 2, 268272 .

Beaman, A. L., Barnes, P. J., Klentz, B. \& McQuirk, B. Increasing helping rates through information dissemination: Teaching pays. Personality and Social Psychology Bulletin, 1978, 4, 406-411.

Bickman, L. The effects of another's ability to help on bystander intervention in an emergency. Journal of Experimental Social Psychology, 1971, $7,367-379$.

Bickman, L. Social influence and diffusion of responsibility in an emergency. Journal of Experimental Social Psychology, 1972, 8 , $438-445$.

Bickman, L. Bystander intervention in a crime: The effect of a massmedia campaign. Journal of Applied Social Psychology, 1975, $\underline{5}$, 296-302.

Bickman, L., \& Green, S. K. Situational cues and crime reporting: Do signs make a difference? Journal of Applied Social Psychology. 1977, ?, $1-18$.

Bickman, L., \& Rosenbaum, D. P. Crime reporting as a function of bystander encouragement, surveillance, and credibility. Journal of Personality and Social Psychology, 1977, 35, 577-586.

Borofsky, G. L., Stollak, G. E., \& Messe, L. A. Sex differences in bystander reactions to physical assault. Journal of Experimental Social Psychology, 1971, 2, 313-318.

Clark, R. D., III, \& Word, L. E. Why don't bystanders help? Because of ambiguity? Journal of Personality and Social Psychology, 1972, $24,392-400$.

Clark, R. D., III, \& Word, L. E. Where is the apathetic bystander? Situational characteristics of the emergency. Journal of Personality and Social Psychology, 1974, 29, 279-287. 
Darley, J. M., \& Batson, D. "From Jerusalem to Jericho": A study of situational and dispositional variables in helping behavior. Journal of Personality and Social Psychology, 1973, 27, 100-108.

Darley, J. M., Latané, B. Bystander intervention in emergencies: Diffusion of responsibility. Journal of Personality and Social Psychology, 1968, ․ 377-383.

Darley, J. M. , \& Latanë, B. The unresponsive bystander: Why doesn't he help? New York: Appleton-Century-Crofts, 1970.

Darley, J. M., Teger, A. I., \& Lewis, L. D. Do groups always inhibit individuals' responses to potential emergencies? Journal of Personality and Social Psychology, 1973, 26, 395-399.

Dertke, M. C., Penner, L. A., \& Ulrich, K. Observer's reporting of shoplifting as a function of thief's race and sex. Journal of Social Psychology, 1974, 94, 213-221.

Festinger, L. Behavioral support for opinion change. The Public Opinion Quarterly, 1964, 28, 404-417.

Gaertner, S. L., \& Dovidio, J. F. The subtlety of white racism, arousal and helping behavior. Journal of Personality and Social Psychology, 1977, 35, 691-707.

Gelfand, D. M., Hartmann, D. P., Walder, P., \& Page, B. Who reports shoptlifters? A field-experimental study. Journal of Personality and Social Psychology, 1973, 25, 276-283.

Greenwald, A. G. Does the good samaritan parable increase helping? A comment on Darly and Batson's no-effect conclusion. Journal of Personality and Social Psychology, 1975, 32, 578-583.

Hayduk, L. A. Personal space: An evaluation and orienting overview. Psychological Bulletin, 1978, 85, 117-135.

Huston, T. L., Geis, G., Wright, R., \& Garrett, T. Good samaritan as crime victims. Victimology, 1973, $1,284-294$.

Hyman, H. H., \& Sheatsley, P. B. Some reasons why information campaigns fail. Public Opinion Quarterly, 1947,11, 413-423.

Korte, C. Effects of individual responsibility and group communication on help giving in an emergency. Human Relations, 1971, 24, 149-159.

Latané, B., \& Darley, J. M. Group inhibition of bystander intervention in emergencies. Journal of Personality and Social Psychology, 1968, 10, 215-221.

Latané, B., \& Darley, J. M. Bystander "apathy", American Scientist, $1969,57,244-268$. 
Latané, B., \& Darley, J. M. The unresponsive bystander: Why doesn't he help? New York: Appleton-Century-Crofts, 1970.

Latané, B., \& Elman, D. The hand in the till. In B. Latané and J. M. Darley, The unresponsive bystander: Why doesn't he help? New York: Appleton-Century-Crofts, 1970.

Latané, B., \& Rodin, J. A lady in distress: Inhibiting effects of friends and strangers on bystander intervention. Journal of Experimental Social Psychology, 1969, 5, 189-202.

Moriarty, T. Crime, commitment, and the responsive bystander: Two field experiments. Journal of Personality and Social Psychology, $1975,31,370-376$.

Piliavin, I. M., Piliavin, J: A., \& Rodin, J. Costs diffusion and the stigmatized victim. Journal of Personality and Social Psychology, $1975,32,429-438$.

Piliavin, I. M., Rodin, J., \& Piliavin, J. A. Good Samaritanism: An underground phenomenon. Journal of Personality and Social Psychology, 1969, 13, 289-299.

Piliavin, J. A., \& Piliavin, I. M. Effect of blood on reactions to a victim. Journal of Personality of Social Psychology, 1972, 23, 353-361.

Piliavin, J. A., Piliavin, I. M., \& Broll, L. Time of arrival at an emergency and likelihood of helping. Personality and Social Psychology Bulletin, 1976, 2, 273-276.

Piliavan, J. A., \& Walster, E. Equity and the innocent bystander. Journal of Social Issues, 1972, 28, 165-190.

Rokeach, M., \& Kliejunas, P. Behavior as a funciton of attitudetoward-object and attitude-toward-situation. Journal of Personality and Social Psychology, 1972, 22, 194-201.

Rosentahal, A. M. Thirty-eight witnesses. New York: McGraw-Hill, 1964.

Ross, A. S. Effect of increased responsibility on bystander intervention: The presence of children. Journal of Personality and Social Psychology, 1971, 19, 306-310.

Ross, A. S., \& Braband, S. Effect of increased responsibility on bystander intervention, II: The cue value of a blind person. Journal of Personality and Social Psychology, 1973, 25, 254-258.

Schwartz, S. H., \& Clausen, G. T. Responsibility norms, and helping in an emergency. Journal of Personality and Social Psychology, $1970,16,299-310$. 
Schwartz, S., \& David, A. B. Responsibility and helping in an emergency: Effects of blame ability and denial of responsibility. Sociometry, 1976, 39, 406-415.

Schwartz, S. H., \& Gottlieb, A. Bystander reactions to a violent theft: Crime in Jerusalem. Journal of Personality and Social Psychology, 1976, 34, 1188-1199.

Shotland, R. L., \& Straw, M. K. Bystander response to an assault: When a man attacks a woman. Journal of Personality and Social Psychology, 1976, 34, 990-999.

Smith, R. E., Smythe, L., \& Lien, D. Inhibition of helping behavior by a similar or dissimilar nonreactive fellow bystander. Journal of Personality and Social Psychology, 1972, 23, 414-419.

Smith, R. E., Vanderbilt, K., \& Callen, M. B. Social comparison situational ambiguity, and bystander intervention. Journal of Applied Social. Psychology, 1973, 3, 376-383.

Solomon, L. Z., \& Grota, P. Imitation of a helpful model: The effect of level of emergency. Journal of Social Psychology, 1976, 99, 29-35.

Staub, E. A child in distress: The effects of focusing responsibility on children on their attempts to help. Developmental Psychology, 1970, 2, 152-154. (a)

Staub, E. A child in distress: The influence of age and number of witnesses on children's attempts to help. Journal of Personality and Social Psychology, 1970, 14, 130-140. (b)

Staub, E. A child in distress: The influence of nurturance and modeling on children's attempts to help. Developmental Psychology, $1971,5,124-132$. (a)

Staub, E. Helping a person in distress: The influence of implicit and explicit "rules" of conduct on children and adults. Journal: of Personality and Social Psychology, 1971, 17, 137-144. (b)

Staub, E. Helping a distressed person. In L. Berkowitz (Ed.), Advances in experimental social psychology (Vol. 7). New York: Academic Press, 1974.

Staub, E., \& Baer, R. Stimulus characteristics of a sufferer and difficulty of escape as determinants of helping. Journal of Personality and Social Psychology, 1974, 30, 279-284.

Steffensmeir, D., \& Terry, R. Deviance and respectability: An observational study of reactions to shoplifting. In D. Katkin, D. Hyman, \& J. Kramer (Eds.), Juvenile delinquency and the juvenile justice system. North Scituate, Mass.: Duxbury Press, 1976. 
Weiner, F. G. Altruism, ambiance; and action: The effects of rural and urban rearing on helping behavior. Journal of Personality and Social Psychology, 1976, 34, 112-124.

Wilson, J. P. Motivation, modeling, and altruism: A person X situation analysis. Journal of Personality and Social Psychology, 1976, 34, 1078-1086. 
Table 1

Predicted Responses of Observer

cost of no help to victim
Cost of Direct Help

Low High

$\begin{array}{lll}\text { High } & \begin{array}{c}\text { Indirect intervention } \\ \text { or }\end{array} \\ & \begin{array}{c}\text { of } \\ \text { redefinition of } \\ \text { situation, } \\ \text { disparagement of } \\ \text { victim, etc. }\end{array} \\ \text { Low } & \begin{array}{l}\text { variable (largely } \\ \text { a function of } \\ \text { perceived norms } \\ \text { in situations) }\end{array} & \begin{array}{l}\text { Leaving scene, } \\ \text { ignoring, denial, } \\ \text { etc. }\end{array}\end{array}$


Table 2

Percentage of People Reporting as a Function of

Type of Information and Method of Dissemenation

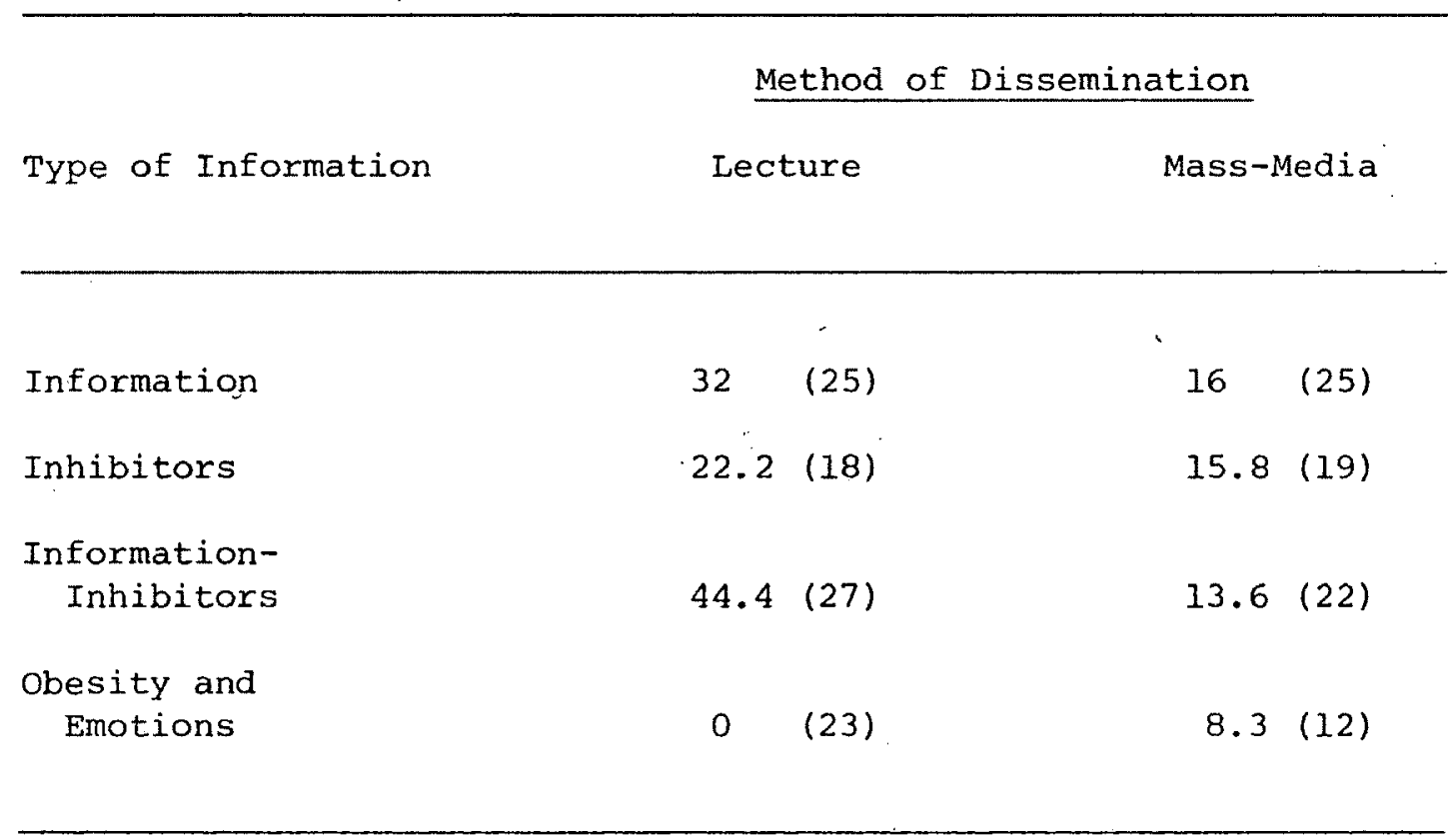

Note: The number in parentheses indicate the number of subjects. 
Table 3

Percentage of Nonsuspicious Subjects

Reporting as a Function of Type of Information

and Method of Dissemination

\begin{tabular}{|c|c|c|c|}
\hline \multirow{3}{*}{$\begin{array}{l}\text { Type of Information } \\
\text { Information }\end{array}$} & \multicolumn{3}{|c|}{ Method of Dissemination } \\
\hline & Lecture & Mass- & Media \\
\hline & $17.6(17)$ & 9.5 & (2I) \\
\hline Inhibitors & $26.7(15)$ & 0 & (11) \\
\hline $\begin{array}{l}\text { Information- } \\
\text { Inhibitors }\end{array}$ & $33.3(18)$ & 10 & $(20)$ \\
\hline $\begin{array}{r}\text { Obesity and } \\
\text { Emotions }\end{array}$ & $(20)$ & 8.3 & $(12)$ \\
\hline
\end{tabular}

Note: The number in parentheses indicates the number of subjects. 